\title{
Immigration: Costs, Benefits and Policy Implications
}

\author{
Bhavya Visal
}

\begin{abstract}
Since 2000, the total number of international migrants has increased by almost 50 percent to 258 million persons globally in 2017 [1]. This paper discusses the effects of immigration on countries' economies and labour markets, analysing the effects on key metrics such as economic growth, productivity, welfare and wages through various perspectives, while also recommending suitable policies.
\end{abstract}

Index Terms - economics, immigration, policies.

\section{INTRODUCTION}

Immigration is unarguably one of the most significant social transformations ofthe twenty-first century. In fact, $15 \%$ of the global population - over 750 million people - would migrate if they could [2]. From the United States to the European Union to the Russian Federation, our world has become increasingly interconnected, with the effects of immigration touching lives across the globe.

Although the significance of immigration in today's world is widely acknowledged, there is much disagreement about its economic effects on stakeholders - host countries, origin countries of

immigrants and the migrants themselves. This paper discusses the effects of immigration on countries' economies and labour markets, analysing the effects on key metrics such as economic growth, productivity, welfare and wages through various perspectives, while also recommending suitable policies.

\section{IMMIGRATION: A BOON}

Proponents of immigration argue that the phenomenon has an overall positive effect on global economic growth and welfare, with gains from free movement of labour ranging from 50-150 percent of global GDP[3]. In Figure 1.0, the benefits of free international migration are shown in a simplistic model, with the shaded area depicting the large welfare gain, as a result of overcoming deadweight loss. Host countries may also benefit from immigration surplus (Figure 1.1) - a net increase in wealth enjoyed by the native population due to an inflow of immigrants. Figure 1.2 depicts this immigration surplus for different assumptions of native skill levels [4].

Depending on whether the immigrants are high-skilled or low-skilled, they can positively contribute to the economy in different ways. Highly skilled workers can bolster economic growth by increasing productivity, introducing new skills and innovation (such as information technology), and creating employment opportunities by setting up businesses or increasing demand for complementary skills.

Bhavya Visal, Inventure Academy Bangalore

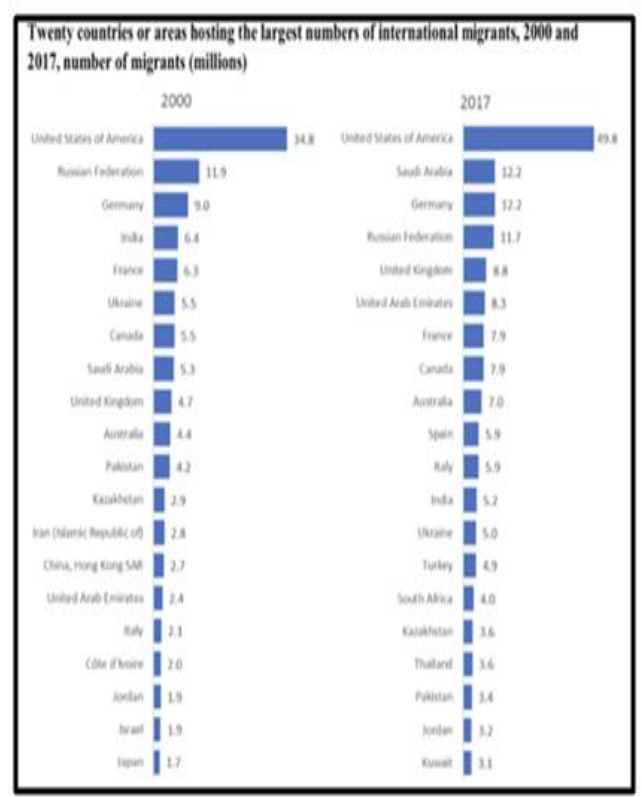

Source: United Nations (2017a)

Notes: "China, Hong Kong SAR" refers to China, Hong Kong Special Administrative Region

Figure 1.1
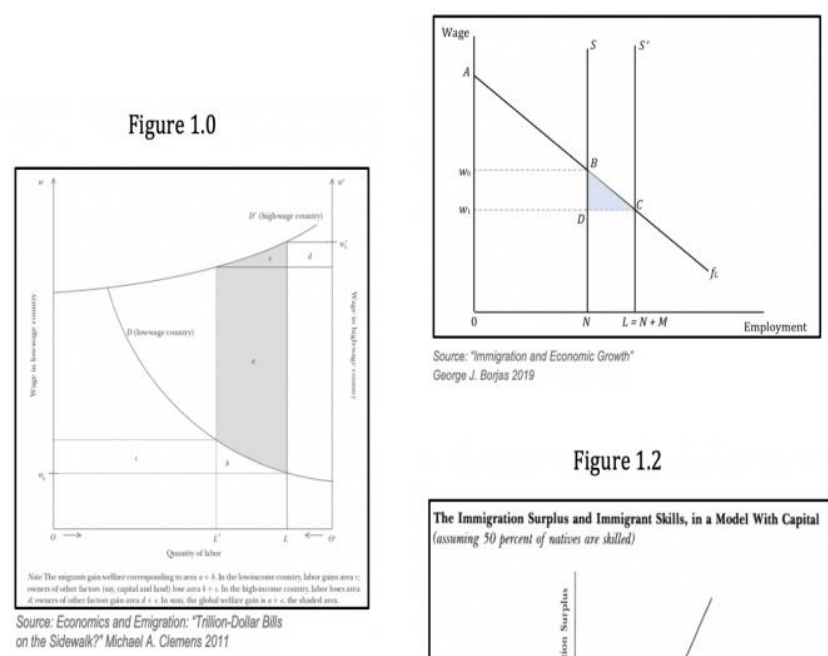

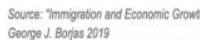

Figure 1.2

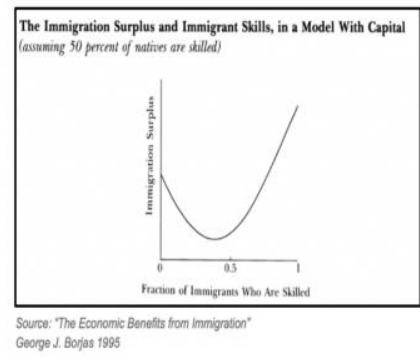

In addition, high-skilled immigration can also reduce the tax burden on the native population and the government. This is because they are likely to spend far more on taxes than consume public goods and may be a fiscal benefit [5]. Low-skilled workers, on the other hand, can take up low-income and less skilled jobs, as they may "do jobs that natives don't want to do" [6] allowing native workers to upskill and enjoy higher wages and living standards. It is 
argued that an increase in immigration may actually increase native wages, assuming that immigrants take on jobs requiring physical skills [5]. In general, migrants also boost the economy indirectly by expanding demand due to increased consumption of goods and services.

Immigration may alsoresult in innovation and product diversity, improving the country's economic development via brain gain. Brain gain is the influx of skills and ideas to a nation, and occurs when "talented scientists, engineers, and other technical personnel that boost innovation" [7] enter an economy. In fact, $52.4 \%$ of the founders of engineering and technology companies in Silicon Valley are immigrants [8].

Another benefit of immigration is its ability to offset the serious challenge of demographic shifts due to ageing populations and shrinking workforces globally, by overcoming labour shortages [9]. According to the Ministry of Trade and Industry in Singapore (2012), an influx of immigrant labour into the workforce is a long-term approach to solving the relevant demographic concerns.

Not only does the host country benefit from immigration, but the country of origin of the migrants does too. For many migrant families, remittance flows serve as financial lifelines [10]. According to the International Fund for Agricultural Development (IFAD), around 800 million people worldwide are directly supported by remittances from relatives abroad [10]. These financial remittances contribute to economic development in many ways: raising families out of poverty, improving their health, sanitation and housing conditions, increasing education opportunities for children, promoting entrepreneurship, and reducing inequality [11].

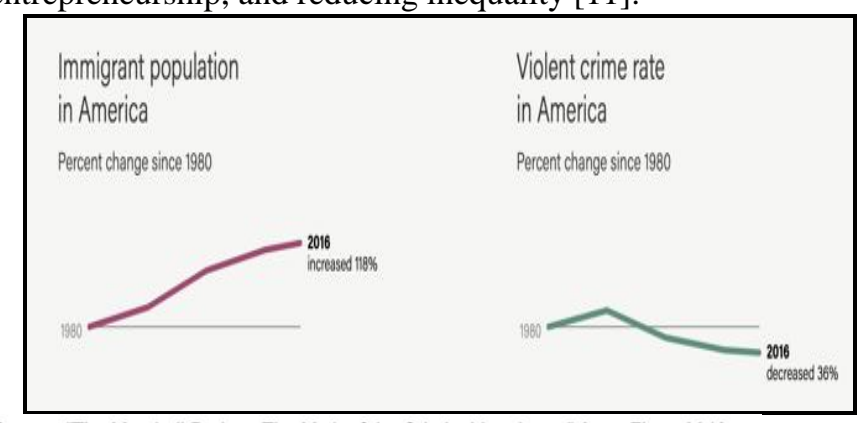

Source: "The Marshall Project: The Myth of the Criminal Immigrant" Anna Flagg 2018

Furthermore, immigration can improve many societal aspects for native workers as well. Apart from increased diversity and appreciation of new cultures as they all coexist, immigration is often correlated with a fall in crime [12].

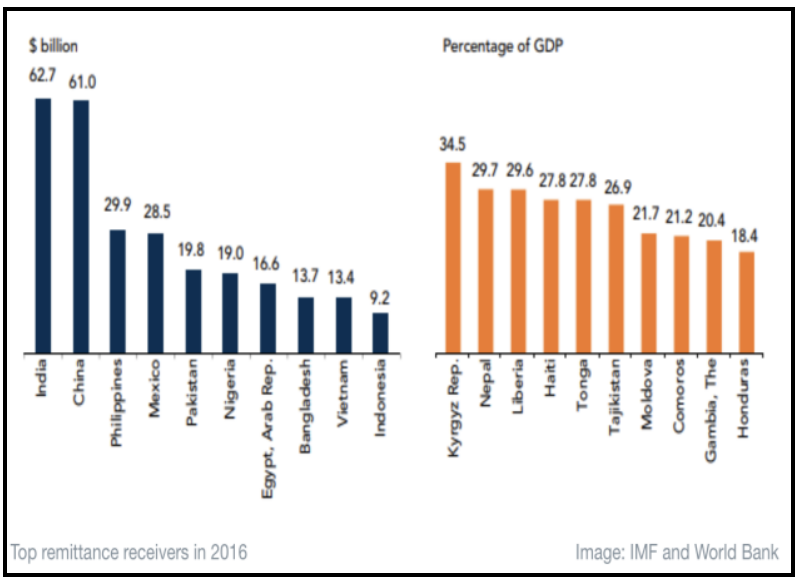

In the long-run, positive externalities of migration may be enjoyed by both the sending and receiving countries, such as agglomeration effects created by talent clusters and productivity spillovers. Highly skilled immigrants may introduce human capital externalities in host countries, increasing the productivity of natives through the sharing of knowledge and skills In addition, immigrants may transfer new ideas and skills that they learn backto their home country too.

\section{IMMIGRATION: A BANE}

Opponents of immigration point out its possible detrimental effects in terms of increased inequality, fiscal burden, unemployment, brain drain and negative externalities.

Immigration may result in greater inequality. It can be said to have contributed to the rise of inequality in the workforce, and the presence of immigrants can explain about $5 \%$ of the rise in overall wage inequality in the United States between 1980 and 2000 [13]. The influx of highly skilled immigrants may raise the wages of the average local high-skilled industry workers through agglomeration or increased demand for complementary skills [14][15]. This may result in the widening of the income difference between low-skilled and high-skilled workers, indicating a rise in inequality.

In addition, the influx of migrants may increase competition for jobs in the labour market. If native workers have substitutable skills, they may face lower wages or even unemployment, thereby reducing their standard of living. It is suggested that through a theoretical lens, immigration must lower the wages of natives [16].

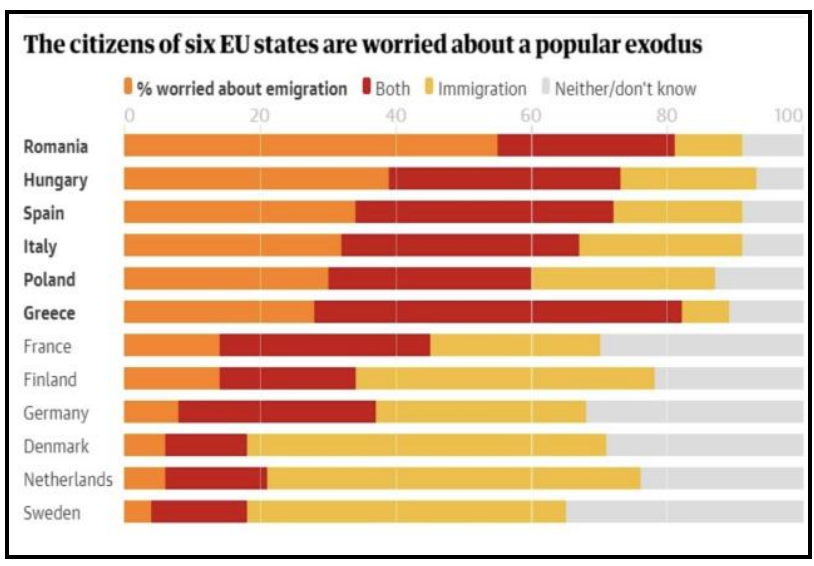

Source: The Guardian newspaper

Another disadvantage of immigration may be increased fiscal burden on the government and native taxpayers, due to increased demand for public goods. High-skilled immigrants may have dependent family members (children and people of oldage) who require social services. However, this is unlikely to burden the government as much since high-skilled immigrants contribute significantly to tax revenue. However, the influx of low-skilled immigrants may heavily burden the government, as they do not contribute much to tax revenue but rather put severe pressure on social assistance programs such as healthcare and education. Research suggests that "the major drain on government finances from immigration comes from public education", implying that the children of 
immigrants heavily contribute to the host government's fiscal drain [17].

Brain drain is an important area of concern for origin countries [18]. At the heart of this concern is the view that high-skilled workers create positive externalities for society, which are lost when they emigrate. Hence, the negative externalities experienced by the immigrant sending country include loss of productivity, lower economic growth and a reduction in the provision of key public services with positive externalities (such aseducation and health due to the emigration of skilled professors and doctors). These countries may also face negative pecuniary externalities due to a significant reduction in tax revenue. There are several economists that support the view that skilled migration is unambiguously detrimental for those left behind [19] [20][21][22].

\section{POLICY IMPLICATIONS}

With a rapid decline in transportation and telecommunication costs, every corner of the world is now more connected than ever before, allowing for increased movement of labour. Given the size of the potential welfare gains from migration, policies need to be crafted to ensure that these gains are distributed fairly between the various stakeholders: sending and receiving countries, capital owners and workers, as well as native and immigrant workers. In this paper, several existing migration policies are analysed.

There are many variations of immigration policies across the world, and they can be summarised into the following [23]:

1. Migration for family reunification - This refers to the migration of workers' dependent family members. In fact, in the European Union, family reunification accounts for about one third of all immigration. The disadvantages of this policy include misuse and a high fiscal burden on the government due to increased demand for social services and public goods such as healthcare and education caused by dependents.

2. Temporary migration - Temporary migration is deemed as advantageous to the receiving country as it allows greater flexibility in adjusting labour supply to the country's economic requirements. Oftentimes, these jobs "at the bottom of the social scale exert little attention and display chronic labour shortages, which foreigners are ready to fill" [24]. On the other hand, the host country may face difficulties integrating migrants into the workforce due to socio-economic differences such as language barriers.

3. High-skilledmigration - The potential benefits of high-skilled immigration are widely acknowledged. In fact, between 2005 and 2011, the percentage of governments that had policies to encourage immigration of highly skilled workers increased both in more developed regions and less developed regions (including least developed countries) [23].

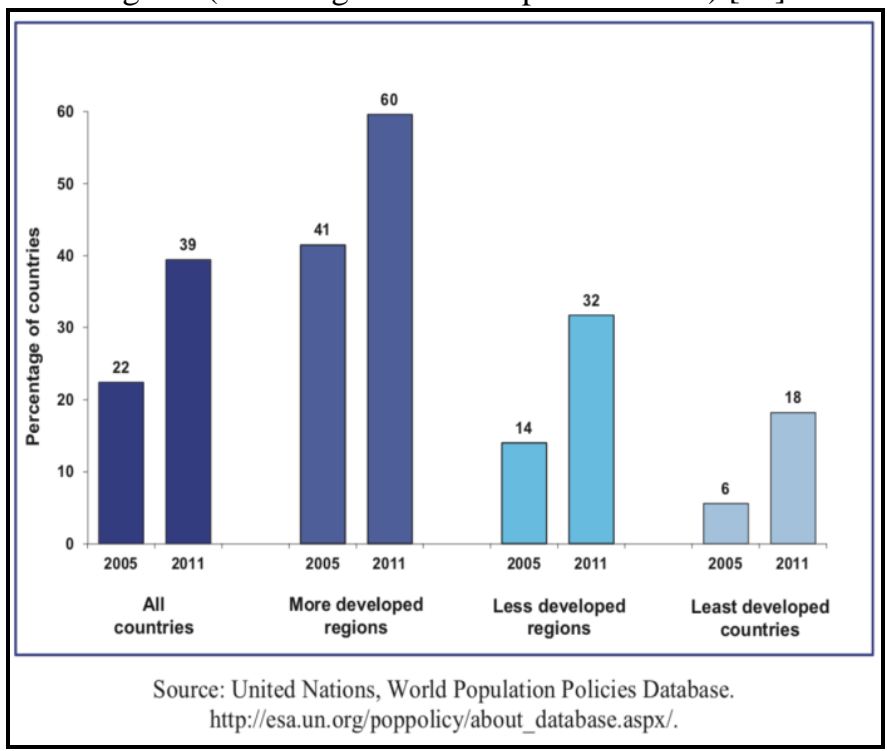

There are broadly two types of policies promoting high-skilled immigration:

1. Immigrant-driven: This approach is a supply-side approach with a points or merit-based system, focusing on screening of individual applicants. Canada and Australia have implemented this policy using formulae and points to accurately and efficiently determine eligibility for a work visa based on several characteristics including education, language skills, work experience and existing employment arrangements. However, the selection process must be reliable, preventing migrants from misrepresenting their qualifications. Another disadvantage includes a mismatch of labour supply and demand, resulting in possible underemployment of migrants and under-utilisation of their skills once they arrive in the host country.

2. Employer-driven: This policy type can be referred to as a demand-side policy as firms select a certain number of skilled workers to allow into the country. For example, in the United States, the H-1B and L1 visas are the primary categories. An advantage of this policy is that migrant workers are guaranteed a job upon arrival. On the other hand, if the quota is set too low, it may prevent the economy from reaching its productive potential. Also, since the employee is bound to his employer, his negotiating ability falls, leaving him susceptible to exploitation.

With regard to highly skilled emigrants, governments policies aimed at fostering their return can be broadly classified into [25]:

1. Migrant network policies - An example of utilising migrant networks is India - the Ministry of Overseas Indian Affairs has been actively engaged with members of migrant communities to further enhance flows of remittances and investments [26].

2. Temporary return programmes - Many countries have policies that promote the temporary return of 
emigrants. For example, the Chinese Government has attracted overseas Chinese scientists by permitting them to work in a second lab in China where they can spend part of their time [25].

3. Permanent return programmes - Countries can encourage permanent return of emigrants through incentives such as tax cuts and attractive research facilities. For instance, qualified Chinese scientists selected through the "100 Talents Program" receive a research grant, office space and other incentives, including competitive salaries and housing allowances [27].

However, these policies may have high fiscal and administrative costs, and the benefits may not outweigh the costs.

Clearly, none of the policies above provide an all-encompassing solution to the complex and dynamic global problem of migration. Therefore, in conclusion, it is imperative that countries engage in an in-depth cost-benefit analysis, with a spotlight on their specific circumstances and economic aims, in order to implement the most socially, politically and economically viable immigration policies.

\section{REFERENCES}

[1] (UN DESA, 2017)

[2] (Wood, 2019)

[3] (Clemens, 2011)

[4] (Borjas, 1995)

[5] (Caplan, 2012)

[6] (Borjas 2018, p332)

[7] (Hanson 2012, p26)

[8] (Wadhwa 2012, p89)

[9] (Partington, 2018)

[10] (Swing, 2018)

[11] (Adams Jr., Chellaraj, Docquier, Marfouk, Martínez, Maskus, et al., 2006)

[12] (Flagg, 2018)

[13] (Card, 2009)

[14] (Kerr, Kerr, Özden, and Parsons, 2016)

[15] (Johnson, 1997)

[16] (Borjas, 2003)

[17] (Hanson 2012, p30)

[18] (Kampouris, 2019)

[19] (Grubel and Scott, 1966)

[20] (Johnson, 1967)

[21] (Bhagwati and Hamada, 1974)

[22] (Kwok and Leland, 1982)

[23] (UN DESA, 2013)

[24] (OECD, 2001)

[25] (Jonkers, 2008)

[26] (India, Ministry of Overseas Indian Affairs, 2013)

[27] (Chinese Academy of Sciences, 2009) 